\title{
Nutritional Knowledge and Practices Among Expectant Mothers in Olorunda Local Government Area, Osogbo Osun State
}

\author{
Olariike Oyindasola Kayode ${ }^{1,}$,, Quadri Kunle Alabi ${ }^{2}$, Adeola Oluwaseun Oshineye ${ }^{1}$ \\ ${ }^{1}$ Department of Public Health, Adeleke University, Ede, Nigeria \\ ${ }^{2}$ Department of Physiology, Adeleke University, Ede, Nigeria
}

Email address:

okeyoyinolariike@yahoo.com (O. O. Kayode)

${ }^{*}$ Corresponding author

\section{To cite this article:}

Olariike Oyindasola Kayode, Quadri Kunle Alabi, Adeola Oluwaseun Oshineye. Nutritional Knowledge and Practices Among Expectant Mothers in Olorunda Local Government Area, Osogbo Osun State. International Journal of Food Science and Biotechnology.

Vol. 6, No. 3, 2021, pp. 66-72. doi: 10.11648/j.ijfsb.20210603.11

Received: July 24, 2021; Accepted: August 6, 2021; Published: August 23, 2021

\begin{abstract}
Maternal nutrition before and during pregnancy is an important determinant of birth weight, high rate of low birth weight in developing countries has been attributed to poor maternal nutrition. The study assessed the nutritional knowledge and practices among expectant mothers in Olorunda Local Government Area, Osogbo Osun State. A Cross-Sectional study was conducted among 290 pregnant women between ages 15 to 49. A self-administered questionnaire was used to collect information on socio-demographic characteristics, nutritional knowledge and practices of respondents. Larger percentage $(85.9 \%)$ of respondents had good nutritional knowledge and $14.1 \%$ had poor knowledge. Also, $81.7 \%$ had good nutritional practice while $18.3 \%$ had poor nutritional practice. Data was analyzed using descriptive and inferential statistics, using chisquare there was no association between nutritional knowledge and age $\left(\mathrm{X}^{2}=2.911, \mathrm{p}\right.$ - value $\left.=0.573\right)$. There was an association between knowledge and level of education $\left(X^{2}=13.713, p-\right.$ value $\left.=0.003\right)$ and there was no significant relationship between nutritional knowledge and nutritional practice of expectant mothers $\left(\mathrm{X}^{2}=1.195\right.$, $\mathrm{p}$-value $\left.=0.188\right)$. Nutritional knowledge and practice is high among expectant mothers in this study. However, women with no formal education had poor nutritional knowledge and practices and should be the target for nutrition education intervention.
\end{abstract}

Keywords: Nutrition, Knowledge, Practice and Expectant Mothers

\section{Introduction}

Nutritional knowledge has been proven to play a vital role in adopting optimal health of every expectant mothers. Maternal nutrition before and during pregnancy is an important determinant of birth weight, high rate of low birth weight in developing countries has been attributed to poor maternal nutrition [1]. There is abundant epidemiological evidence that poor prenatal nutrition predisposes the offspring to diseases in its later life [2-4]. Inadequate nutrition is the predominant factor leading to malnutrition, which can be expressed as either undernutrition or overnutrition. Undernutrition occurs when there is not only inadequate energy but also a lack of imbalance of specific food components and nutrients.
In addition to sufficient energy, adequate supplies of macronutrients and micronutrients are required to promote optimum growth. It has been recognized that pregnant and lactating women form one of the most nutritionally vulnerable segments of the population; the ill effects of maternal under nutrition affect not only the mother but also her offspring. Many women who became pregnant in developing countries, suffers from ongoing nutritional deficiencies, repeated infections and the long term cumulative consequences of under nutrition during their childhood [5].

Most women suffer from a combination of chronic energy deficiencies, as well as infections like HIV and malaria [6]. 
These along with inadequate obstetric care contribute to the high rate of maternal mortality and poor birth outcome.

Nutritional knowledge refers to that aspect of education that prepares one for meaningful nutritional practices [7]. It was emphasized that every living thing has the right to have access and the right to affordability of nutritious food and at when due.

Nutritional knowledge without practice is not meaningful. Nutritional practice is outward demonstration of nutritional knowledge in the homes, outside the homes and even in social gatherings [8].

Nutritional knowledge and practices are being emphasized upon because of their role in determining the pregnancy outcome as well as the state of health of the mother after childbirth [9]. Also, Karger and Basel emphasized that nutrition is important to expectant mothers because it can spell the difference between a healthy new born and a sickly child [10]. This study was therefore conducted to assess the nutritional knowledge and nutritional practices of expectant mothers in Olorunda Local Government Area in Osogbo Osun state.

\section{Materials and Methods}

\subsection{Study Design}

The study was a cross-sectional descriptive study

\subsection{Subjects}

The study was conducted using pregnant women between 15 to 49 years, who registered for antenatal care with primary health centres in Olorunda Local Government, Osogbo Osun State. Two hundred and ninety (290) pregnant women participated in the study.

\subsection{Sampling Technique}

Four Primary Health Care Centres (Ota Efun Health Centre, Sabo Health Post, Kelebe Health Centre and Akogun Health Centre) were selected from Olorunda Local Government Area by simple random sampling.

\subsection{Data Collection}

After obtaining written informed consent from the study subjects, data on socio-demographic characteristics, nutritional knowledge and nutritional practices were obtained by the administration of structured questionnaires.

In view of the descriptive nature of the study, the questionnaire was made up of 3 section, Section A, contained the personal data of the respondents (Socio demographic characteristics). Section $\mathrm{B}$, involved fourteen questions on nutritional knowledge.

Section C, contained nine questions on nutritional practices. The questionnaire responses in Section B was structured in two point scale of Yes \{\} and No \{\} in Section $\mathrm{C}$, the responses were in three point scale of practice always (PA), Practice rarely (PR) and do not practice (DP). Practice always was defined as those that consumed the given food on a daily basis, practice rarely was defined as those that consumed the food once in a week or less.

\subsection{Data Analysis}

Data was analyzed using Statistical Package for services solution (SPSS) version 21. Percentages and chi square test trend was used to analyze the data. All $\mathrm{P}$ values of less than 0.05 was considered as statistically significant

\subsection{Operational Definitions}

Knowledge: This refers to the awareness of the respondents about balanced diet and the food sources of nutrients.

Good Knowledge: If respondents score $\geq 50 \%$ (out of $100 \%$ ) on the knowledge questions.

Poor knowledge: If respondents score $<50 \%$ (out of $100 \%$ ) on the knowledge questions.

\subsection{Practice}

This is the habitual consumption of foods that could affect the nutritional status of respondents.

\subsubsection{Good Practices}

This is when the pregnant mothers include fruits, vegetables, meat, milk and milk products in their diet at least once per day, and for frequency of four or more meals per day.

\subsubsection{Bad Practices}

This is when the pregnant mothers include fruits, vegetables, meat, milk and milk product in their diet once per week and meal frequency less than three times per day.

\section{Results}

Table 1 shows the socio - demographic characteristics of respondents. One hundred $(34.5 \%)$ of the respondents were within the age range $30-34,88(30.3 \%)$ were within the age range $35-39,84(29 \%)$ were within the age range $25-29,9$ (3.1\%) were within the age range $15-24$ and $9(3.1 \%)$ were within the age range $40-45$.

Most of the respondents $272(93.8 \%)$ were married, 13 $(4.5 \%)$ respondents were single, $3(1 \%)$ were separated while two $(0.7 \%)$ were divorced.

Table 2 shows the nutritional knowledge of respondents, the overall knowledge score showed that larger percentage $(86 \%)$ of respondents had good nutritional knowledge and $14 \%$ had poor knowledge (Figure 1).

Table 3 shows nutritional practice of respondents, the overall nutritional practice showed that $81.7 \%$ had good nutritional practice while $18.3 \%$ had bad nutritional practice (Figure 2). 
Table 1. Socio-demographic characteristics of respondents $(N=290)$.

\begin{tabular}{|c|c|}
\hline VARIABLES & FREQUENCY (\%) \\
\hline \multicolumn{2}{|l|}{ AGE } \\
\hline $20-24$ & $9(3.1)$ \\
\hline $25-29$ & $84(29.0)$ \\
\hline $30-34$ & $100(34.5)$ \\
\hline $35-39$ & $88(30.3)$ \\
\hline $40-44$ & $9(3.1)$ \\
\hline MEAN AGE & 31.97years \\
\hline \multicolumn{2}{|l|}{ RELIGION } \\
\hline Christianity & $139(48.0)$ \\
\hline Islam & $148(51.0)$ \\
\hline Traditional & $3(1.0)$ \\
\hline \multicolumn{2}{|l|}{ ETHNICITY } \\
\hline Yoruba & $192(66.2)$ \\
\hline Hausa & $63(21.7)$ \\
\hline Igbo & $35(12.1)$ \\
\hline \multicolumn{2}{|l|}{ MARITAL STATUS } \\
\hline Single & $13(4.5)$ \\
\hline Married & $272(93.8)$ \\
\hline Divorced & $2(0.7)$ \\
\hline Separated & $3(1.0)$ \\
\hline \multicolumn{2}{|c|}{ NUMBER OF PREGNANCY } \\
\hline $1-3$ & $105(36.2)$ \\
\hline $4-5$ & $173(59.7)$ \\
\hline 6 and above & $12(4.1)$ \\
\hline \multicolumn{2}{|l|}{ TRIMESTER } \\
\hline First & $35(12.1)$ \\
\hline Second & $180(62.1)$ \\
\hline Third & $75(25.8)$ \\
\hline \multicolumn{2}{|c|}{ LEVEL OF EDUCATION } \\
\hline No formal education & $14(4.8)$ \\
\hline Primary & $40(13.8)$ \\
\hline Secondary & $83(28.6)$ \\
\hline Tertiary & $153(52.8)$ \\
\hline \multicolumn{2}{|l|}{ OCCUPATION } \\
\hline Trading & $122(42.1)$ \\
\hline Teaching & $49(16.9)$ \\
\hline Civil Servant & 49 (16.9) \\
\hline Self-employed & $51(17.6)$ \\
\hline Unemployed & $19(6.6)$ \\
\hline \multicolumn{2}{|c|}{ ESTIMATED INCOME (\#) } \\
\hline$<10000$ & $71(24.5)$ \\
\hline $10000-30000$ & $168(57.9)$ \\
\hline $31000-50000$ & $42(14.5)$ \\
\hline$>50000$ & $9(3.1)$ \\
\hline
\end{tabular}

Table 2. Nutritional knowledge of expectant mothers $(N=290)$.

\begin{tabular}{|c|c|c|}
\hline Variables & Frequency & Percentage (\%) \\
\hline \multicolumn{3}{|c|}{ Heard of balanced diet } \\
\hline Yes & 253 & 87.2 \\
\hline No & 37 & 12.8 \\
\hline \multicolumn{3}{|c|}{ Eating balanced diet is vital to the mother and baby during pregnancy } \\
\hline Yes & 256 & 88.3 \\
\hline No & 34 & 11.7 \\
\hline \multicolumn{3}{|c|}{$\begin{array}{l}\text { Balanced diet in pregnancy helps in boosting the immunity of the mother } \\
\text { and the baby }\end{array}$} \\
\hline Yes & 222 & 76.6 \\
\hline No & 68 & 23.4 \\
\hline \multicolumn{3}{|c|}{ Eating food rich in folate during pregnancy can help to prevent birth defect } \\
\hline Yes & 208 & 71.7 \\
\hline No & 82 & 28.3 \\
\hline \multicolumn{3}{|c|}{$\begin{array}{l}\text { Consuming food rich in calcium help the baby to develop strong bone an } \\
\text { teeth }\end{array}$} \\
\hline Yes & 248 & 85.5 \\
\hline No & 42 & 14.5 \\
\hline
\end{tabular}

\begin{tabular}{lcc}
\hline Variables & Frequency & Percentage (\%) \\
\hline Yes & 278 & 95.9 \\
No & 12 & 4.1 \\
Skipping of meals during pregnancy is harmful to the & mother and the foetus. \\
Yes & 192 & 66.2 \\
No & 98 & 33.8 \\
Eating of fruits and vegetables during pregnancy helps to improve the iron \\
status of pregnant women \\
Yes & 239 & 82.4 \\
No & 51 & 17.6 \\
\hline
\end{tabular}

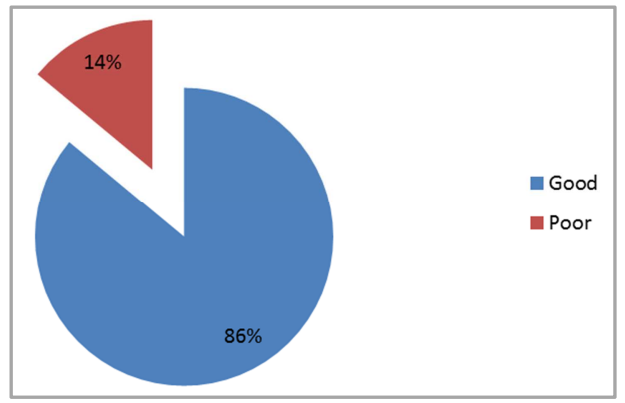

Figure 1. Overall nutritional knowledge of respondents.

Table 3. Nutritional practice of expectant mothers.

\begin{tabular}{lcc}
\hline Variables & Frequency & Percentage (\%) \\
\hline How often do you eat fruits and vegetable & \\
Always & 228 & 78.6 \\
Rarely & 62 & 21.4 \\
Never & \\
How often do you eat foods rich in protein? & \\
Always & 254 & 87.6 \\
Rarely & 36 & 12.4 \\
Never & & \\
How often do you take vitamin supplement (e.g. folic acid)? \\
Always & 255 & 87.9 \\
Rarely & 35 & 12.1 \\
Never & & \\
How often do you take mineral supplement (e.g. ferrous)? \\
Always & 209 & 72.1 \\
Rarely & 81 & 27.9 \\
Never & & \\
How often do you consume foods that are rich in calcium (e.g. snail, milk, \\
cheese, yoghurt)? \\
Always & 180 & \\
Rarely & 110 & 62.1 \\
Never & & 37.9 \\
How often do you skip meals? & \\
Always & 29 & 10.0 \\
Rarely & 54 & 18.6 \\
Never & 207 & 71.4 \\
\hline
\end{tabular}

\section{Overall Nutritional Practice of Respondent}

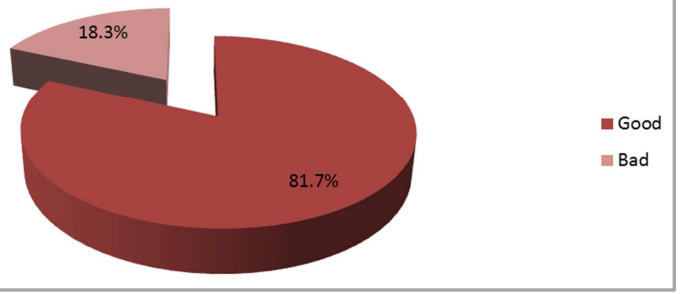

Figure 2. Overall nuritional practice of expectant mothers. 
Table 4. Showing the relationship between socio-demographic characteristics and nutritional knowledge of expectant mothers (N=290)

\begin{tabular}{|c|c|c|c|c|c|}
\hline VARIABLES & KNOWLEDGE & & $\mathrm{X}^{2}$ & P-value & Comment \\
\hline GOOD (\%) & POOR (\%) & & & & \\
\hline \multicolumn{6}{|l|}{ AGE } \\
\hline $20-24$ & $7(2.41)$ & $2(0.68)$ & 2.911 & 0.573 & NSS \\
\hline $25-29$ & $73(25.17)$ & $11(3.79)$ & & & \\
\hline $30-34$ & $83(28.62)$ & $17(5.86)$ & & & \\
\hline $35-39$ & $77(26.55)$ & $11(3.79)$ & & & \\
\hline $40-45$ & $9(3.10)$ & $\mathrm{LR}^{\mathrm{x} 2}$ & & & \\
\hline \multicolumn{6}{|l|}{ RELIGION } \\
\hline Christianity & $124(42.75)$ & $15(5.17)$ & 3.118 & 0.210 & NSS \\
\hline Islam & $123(42.41)$ & $25(8.62)$ & & & \\
\hline Traditional & $2(0.68)$ & $1(0.3)$ & & & \\
\hline \multicolumn{6}{|l|}{ NUMBER OF PREGNANCY } \\
\hline $1-3$ & $97(33.44)$ & $8(2.75)$ & 6.304 & 0.043 & SS \\
\hline $4-5$ & $143(49.31)$ & $3(1.0)$ & & & \\
\hline$>5$ & $9(3.10)$ & $3(1.0)$ & & & \\
\hline \multicolumn{6}{|l|}{ ESTIMATED INCOME } \\
\hline$<10000$ & $56(19.30)$ & $15(5.17)$ & 3.787 & 0.285 & NSS \\
\hline $10000-30000148(51)$ & $20(6.90)$ & & & & \\
\hline $31000-5000037(12.75)$ & $5(1.7)$ & & & & \\
\hline$>51000$ & $8(2.75)$ & $1(0.3)$ & & & \\
\hline \multicolumn{6}{|l|}{ LEVEL OF EDUCATION } \\
\hline No formal education & $8(2.75)$ & $6(2.06)$ & 13.713 & 0.003 & SS \\
\hline Primary & $31(10.68)$ & $9(3.10)$ & & & \\
\hline Secondary & $74(25.52)$ & $9(3.10)$ & & & \\
\hline
\end{tabular}

NSS: Not statistically significant

SS: Statistically significant

Table 5. Showing the relationship between socio-demographic characteristics and nutritional practice of expectant mothers $(N=290)$.

\begin{tabular}{|c|c|c|c|c|c|}
\hline VARIABLES & PRACTICE & & $\mathbf{X}^{2}$ & P-value & Comment \\
\hline GOOD (\%) & BAD (\%) & & & & \\
\hline \multicolumn{6}{|l|}{ AGE } \\
\hline $20-24$ & $9(3.10)$ & $0(0)$ & 2.911 & 0.573 & NSS \\
\hline $25-29$ & $68(23.44)$ & $16(5.51)$ & & & \\
\hline $30-34$ & $81(27.93)$ & $19(6.55)$ & & & \\
\hline $35-39$ & $72(24.82)$ & $16(5.51)$ & & & \\
\hline $40-45$ & $7(2.41)$ & $2(0.68)$ & & & \\
\hline \multicolumn{6}{|l|}{ RELIGION } \\
\hline Christianity & $124(42.75)$ & $15(5.17)$ & 10.149 & 0.006 & SS \\
\hline Islam & $111(38.27)$ & $37(12.75)$ & & & \\
\hline Traditional & $2(0.68)$ & $1(0.3)$ & & & \\
\hline \multicolumn{6}{|l|}{ ETHNICITY } \\
\hline Yoruba & $147(50.68)$ & $45(15.52)$ & 10.524 & 0.005 & SS \\
\hline Hausa & $59(20.34)$ & $4(1.38)$ & & & \\
\hline Igbo & $31(10.68)$ & $4(1.38)$ & & & \\
\hline \multicolumn{6}{|c|}{ NUMBER OF PREGNANCY } \\
\hline $1-3$ & $83(28.62)$ & $22(7.58)$ & 0.790 & 0.674 & NSS \\
\hline $4-5$ & $144(49.65)$ & $29(10)$ & & & \\
\hline$>5$ & $10(3.45)$ & $2(0.68)$ & & & \\
\hline \multicolumn{6}{|l|}{ ESTIMATED INCOME } \\
\hline$<10000$ & $63(21.72)$ & $8(2.75)$ & 5.267 & 0.153 & NSS \\
\hline $10000-30000132(45.51)$ & $36(12.41)$ & & & & \\
\hline $31000-5000012(4.12)$ & $9(3.06)$ & & & & \\
\hline \multicolumn{6}{|l|}{ LEVEL OF EDUCATION } \\
\hline No formal education & $10(3.45)$ & $4(1.38)$ & 9.471 & 0.024 & SS \\
\hline Primary & $33(11.37)$ & $7(2.41)$ & & & \\
\hline Secondary & $134(46.20)$ & $53(18.27)$ & & & \\
\hline
\end{tabular}

NSS: Not statistically significant

SS: Statistically significant 
Table 6. Showing the relationship between nutritional knowledge and nutritional practice of expectant mothers $(N=290)$.

\begin{tabular}{|c|c|c|c|c|c|c|}
\hline KNOWLEDGE & & PRACTICE & & $\mathbf{X}^{2}$ & P-VALUE & COMMENTS \\
\hline & & GOOD & POOR & 1.195 & 0.188 & $\begin{array}{l}\text { There is no significant relationship between nutritional knowledge } \\
\text { and nutritional practice of expectant mothers. }\end{array}$ \\
\hline & $\begin{array}{l}\text { GOOD } \\
\text { POOR }\end{array}$ & $\begin{array}{l}206(71.03) \\
31(10.68)\end{array}$ & $\begin{array}{l}43(14.82) \\
10(3.45)\end{array}$ & & & \\
\hline
\end{tabular}

Not Statistically Significant (NSS)

\section{Discussion}

\subsection{Nutritional Knowledge of Respondents}

The study revealed that good percentage $(86 \%)$ of the subjects had adequate knowledge of fourteen items testing Knowledge of good nutrition. Larger percentage (87.2\%) of the respondents were knowledgeable about balanced diet and $71.7 \%$ of the respondents agrees that eating food rich in folate can help to prevent birth defects. Almost all respondents $(95.9 \%)$ were aware that consuming balanced diet during pregnancy helps to prevent low birth weight.

However, the number of the expectant mothers' of the study with adequate knowledge of nutrition were greater than the number that actually practiced adequate nutritional practices $(81.7 \%)$. This agrees with the findings of Ochogu where it was observed that nutritional knowledge was greater than nutritional practice among the subjects [8].

While some of them could not put the knowledge into practice agrees with Galli assertion that Knowledge alone did not change behavior but required many factors to motivate an individual to change his/her behaviour [11].

\subsection{Relationship Between Sociodemographic Characteristics and Nutritional Knowledge}

From table 4 it was shown that educational qualification and number of pregnancies (parity) significantly influenced their knowledge and practices of nutrition. This may not be surprising because the higher the level of education the more one will want to have more knowledge in a particular area of life. This result is in line with what Metab observed that a woman's level of education is closely related to her income, and the income of a woman is correlated to her attitude and practices and adequate nutrition. The finding in that study revealed that age, educational level are factors that can influence knowledge, attitude, practices regarding nutrition [12].

Another study conducted in Belgium showed that age, educational level and kind of occupation were significantly associated with nutritional knowledge [13]. This also implies that education, at least to secondary school level is very necessary for girl children, bearing in mind their reproductive role and the overall duty of caring for the family members.

For parity, the result in table 4 showed that the number of children or pregnancies of the expectant mothers of study had significantly influenced their knowledge and practices of nutrition.

From table 4, age, religion and income of subjects was not statistically significant with their nutritional knowledge and practice.
The low level of knowledge and practices observed among the mothers with no parity was not a surprise since this group of women might not be experienced enough about the importance of good nutrition on the outcome of pregnancies. The implication of this is that expectant mothers that are having babies for the first time should be given adequate nutritional counseling because they lack the knowledge.

\subsection{Nutritional Practice of Respondents}

For the nutritional practices, more than half of the respondents $228(78.6 \%)$ reported consuming fruits and vegetables on a daily basis during pregnancy while 62 $(21.4 \%)$ reported the rarely consumption of fruit and vegetable. Skipping of meals was reported among $10 \%$ of the respondents while $71.4 \%$ of the respondents reported they had never skip meals during pregnancy. Larger percentage $255(87.9 \%)$ always take folic acid while 209 (72.1\%) of respondents reported always consumption of iron supplement.

With regards to avoidance of certain foods during pregnancy, the result obtained $(26.9 \%)$ was much lower than a similar study conducted in Borno State where $61.22 \%$ of the respondents avoided foods like eggs, fish, fruits and milo drinks while pregnant [14]. This could be due to taboos regarding consumption of certain diets while pregnant in Nigeria.

The overall nutrition practice of respondents revealed that $81.7 \%$ had good nutritional practice and this was contrary to a study carried out by Zelalem in Addis Ababa where only $34.5 \%$ of respondents had good nutritional practices [15].

\subsection{Relationship Between Sociodemographic Characteristics and Nutritional Practice}

Religion, ethnicity and level of education was found to be associated with nutritional practices of respondents as shown in table 5. This agrees with a similar study in Manzini, Swaziland in which other sociodemographic factor such as religion was found to be significantly associated with practices towards good nutrition [16]

\subsection{Relationship Between Nutritional Knowledge and Nutritional Practice of Respondents}

From table 6 there was no significant association between nutritional knowledge and nutritional practices of subjects. The study showed that larger percentage $(86 \%)$ had good nutritional knowledge and $81.7 \%$ had good nutritional practice. A study carried out in Swaziland showed that nutritional knowledge and attitude among pregnant and lactating women did not necessarily translate to practice [17]. 
Literature has also shown that low socioeconomic status is associated with the consumption of poor and monotonous diets, food insufficiency and the risk of a variety of micronutrient deficiencies is high. Also, cultural beliefs and practices may also impose restrictions to foods eaten by pregnant women of reproductive age [18]

\section{Conclusion}

The study revealed that nutritional knowledge and practices among the study participant was high. Educational level and number of pregnancies (parity) were the significant factors affecting nutritional knowledge of mothers during pregnancy. Also, educational qualification significantly influenced the nutritional practices of respondents. However, women with no formal education still had poor knowledge and practice regarding nutrition during pregnancy which need to be addressed. Also, there is need to educate pregnant women to ignore certain food taboos that hinder proper nutritional practices.

It is recommended that future study should be qualitative in design to gain insights into factors (environmental, sociocultural, biological) affecting nutritional practices during pregnancy.

\section{Conflict of Interests}

The authors declare that they have no competing interests.

\section{Appendix}

QUESTIONNAIRE TO ASSESS NUTRITIONAL KNOWLEDGE AND PRACTICES AMONG EXPECTANT MOTHERS IN OLORUNDA LOCAL GOVERNMENT AREA, OSOGBO, OSUN STATE.

SECTION A: SOCIO-DEMOGRAPHIC CHARACTERISTICS

1) Age (in completed years):

2) Gender: (i) Male \{\}

(ii) Female \{\}

3) Religion: (i) Christianity \{ \}

(ii) Islam \{\}

(iii) Traditional \{\}

4) Ethnicity: (i) Yoruba \{\}

(ii) Hausa \{\}

(iii) Igbo \{\}

5) Marital Status: (i) Single \{\}

(ii) Married \{\}

(iii) Divorced \{\}

iv Separated \{\}

6) No of Pregnancies/births: (i) $1-3\{\}$

(ii) $4-5\{\}$

(iii) 6 and above

7) Trimester/Months: (i) First $(1-3)\{\}$

(ii) Second $(4-6)\{\}$

(iii) Third $(7-9)\{\}$

8) Level of income (\#): (i) Below 10,000\{\}

(ii) $10,000-30,000$

(iii) $31,000-50,000\{\}$

(iv) 51,000 and above \{\}

9) Educational Level: (i) No formal education \{\}

(ii) Primary \{\}

(iii) Secondary \{\}

(iv) Tertiary \{\}
10)Occupation: (i) Trading \{\}
(ii) Teaching \{\}
(iii) Civil servant \{\}

(iv) Self-employed \{\}

(v) Unemployed \{\}

\section{SECTION B: NUTRITIONAL KNOWLEDGE OF EXPECTANT MOTHERS}

$\mathrm{S} / \mathrm{N} \quad$ Variables

11. Have you heard about balanced diet

12. Eating balanced diet is vital to the mother and the baby in the womb during pregnancy.

13. Balance diet is essential for optimal growth and development of the baby.

14. Balance diet in pregnancy helps in boosting the immunity of the mother and the baby.

15. Taking food rich in calcium help the baby to develop strong bones and teeth.

16. Taking food rich in vitamins and minerals during pregnancy is essential for proper growth and development of the baby.

17. Eating food rich in folate during pregnancy can help to prevent birth defects.

18. Balanced diet during pregnancy can help to prevent low birth weight.

19. Skipping of meals during pregnancy is harmful to the mother and the foetus.

20. Pregnant women should eat more than three meals per day.

21. Eating fruits and vegetables during pregnancy helps to improve the iron status of pregnant women.

22. It is beneficial for expectant mothers to reduce their salt intake during pregnancy.

23. It is unsafe to eat fresh fruits and vegetables sprayed with pesticides even after they been washed.

24. It is beneficial to take vitamin and mineral supplement during pregnancy 
$\mathrm{S} / \mathrm{N} \quad$ Variables

25. How often do you eat fruits and vegetables during pregnancy?

26. How often do you eat foods that are rich in carbohydrates (rice, yam, eba) during pregnancy?

27. How often do you eat foods that rich in protein (e.g. beans, milk, egg) during pregnancy?

28. How often do you skip meals during pregnancy How often do you take vitamins supplement (e.g folic acid) during pregnancy?

30. How often do you take mineral supplement (e.g ferrous) during pregnancy? How often do you consume foods that are rich in calcium (e.g. snail, milk, cheese, yoghurt) during pregnancy?

32. How often do you avoid certain foods (e.g. snail, okro, plantain) How often do you consume nuts (e.g. cashew nut, groundnut, walnut) during pregnancy

PA- consumption of the given food on a daily basis

PR - Consumption of the given food once in a week or less

\section{References}

[1] Ogunjuyigbe P. O., Ojofeitimi E. O. Sanusi R. A., Orji E. O., Akinlo A., Liasu S. A., Owolabi O. O. (2008). Food Aversion during pregnancy: A mayor cause of poor pregnancy outcome in Nigeria. Journal of Chinese Clinical Med. Vol. 3, No. 7, pp. 389-398.

[2] McGowan C, McAuliffe F. M. (2012). Maternal dietary patterns and associated nutrient intakes during each trimester of Pregnancy. Public Health Nutrition. Vol 16, issue 1.

[3] Wang, M; Wang Z. P; Gao L. J; Yang, H. Zhao, Z. T. (2015). Maternal consumption of non-staple food in the first trimester and risk of neural tube defects in offspring. Nutrients 7 (5): 3067-3077 DOI: 10.3390/nu7053067.

[4] Wood Bradley, R. Barrand, S. Giot, A. Armitage, J. (2015). Understanding the role of maternal diet on kidney development; an opportunity to improve cardiovascular and renal health for future generations. Nutrients 7, 1881-1905.

[5] Gina MA, Gibbon D, Malhi R, Mamede F (2011). Food Choices and Practices during pregnancyof Immigrant and Aboriginal women. Biomed Central. Pg. 205-211.

[6] Ramlal, R. Tembo, M. King C. C. Ellington S. Soko, A. Chigwenembe M. (2015). Dietary Patterns and maternal anthropometry in HIV-infected, pregnant Malawian womem. Nutrients. 7 (1): 584-594.

[7] Ayo, O. B. (2003). Adequate nutrition: fulfilling our rights to a happy and healthy life. Business Times, pp. 24-26.

[8] Ochogu J. O. (2010). Nutritional Knowledge and Practices among Expectant Mothers in Onitsha North and South Local Government Areas of Anambra State.

[9] Williams, R. D. (2007). Healthy Pregnancy Healthy Baby: Exercise, Good food and parental care are the keys. Achieved September 20, 2008 at $<\ldots / \mathrm{mcjm} /$ email.htm $>$ FDA consumer.

[10] Karger, A. G., \& Basel, S. (2010). Doctors told to Improve Nutrition: Get fit and Lose weight, Tehran: Shahid Beheshti University of medical Science.

$\begin{array}{lll}\text { Practice } & \text { Practice } & \text { Do not } \\ \text { Always (PA) } & \text { rarely (PR) } & \text { practice }\end{array}$

[11] Galli, N. (1998). Foundations and Principles of Health Education. Philadephia: John Willy and Sons Inc.

[12] Metab, A. N. (2010). Nutritional knowledge, attitude and practices of Tehranian adults and their relation to serum lipid and lipoproteins. Journal of Nutrition, Diseases and Dietetics, 56: 233-240.

[13] De Vriendt T, Matthys C, Verbeke W, Pynaert I. De Henauw S (2009). Determinants of nutrition knowledge in young and middle-aged Belgian women and the association with their dietary behaviour. J Appet 52 (3); 788-792.

[14] Kever RT, Martins SD, Lola N, Dathini H., Habu, H., Fatima, A. A., Sambo B. D. (2015). Knowledge and attitude of pregnant women towards dietary practices in Yerwa Clinic, Maiduguri Metropolitan Council; Borno State. J Res erch Nurs Midwif Vol. 4 (1) pp. 12-19.

[15] Zelalem Tenaw, Mikyas Arega and Erdaw Tachbele (2018) Nutritional knowledge, attitude and practices among pregnant women who attend antenatal care at public hospitals of Addis Ababa, Ethiopia. International Journal of Nursing and Midwifery. Vol. 10 (7), pp. 81-89.

[16] Sakhile K. M., Shu-Jan J. L. (2014). Nutritional Knowledge, Attitude, and Practices among Pregnant and Lactating Women Living with HIV in the Manzini Region of Swaziland. J Health Popul Nutr 32: 261-9.

[17] Masuku SK, Lan SJ (2014) Nutritional knowledge, attitude, and practices among pregnant and lactating women living with HIV in the Manzini region of Swaziland. J Health Popul Nutr 32: 261-269. 30.

[18] Ojofeitimi E. O., Ogunjuyigbe P. O., Sanusi R. A., Orji E. O., Akinlo A., Liasu, S. A. and Owolabi O. O. (2008). Poor dietary intake of energy and retinol among pregnant women: implications for pregnancy outcome in Southwest. Nigeria Pakistan Journal of Nutrition Vol. 7 issue 3 pp. 480-484. 